\title{
JOÃO REBALDE, Liberdade humana e perfeicão divina na 'Concordia' de Luis de Molina. Ribeiráo, Húmus, 2015, 214 pp., ISBN: $989755162 X$
}

Libertad humana y perfección divina en la 'Concordia' de Luis de Molina, trata de determinar la importancia que tuvo el hallazgo del carácter condicionado de una noción de libertad de arbitrio y de una ciencia media, que siempre se deberían concebir como en sí mismas revisables, sin poderse ya orientar por unos criterios de validez incondicionados en sí mismos absolutos a diferencia de lo que sucede con la libertad y la ciencia divina. Con la circunstancia añadida de que, además, se habría proporcionado así una definición más correcta de aquellas nociones básicas que a su vez acabarían entrando en conflicto en la llamada controversia «de auxiliis», que se había hecho presente a lo largo del pensamiento neoescolástico de todo el Siglo de Oro español (siglo XVI y XVII), sin tampoco acabarles de dar el correcto planteamiento que habría cabido esperar. Por su parte, João Rebalde considera que la 'Concondia', publicada en Lisboa en 1588, del jesuita Luis de Molina (1535-1600), habría originado la consiguiente polémica «De auxiliis» que a su vez mantuvo con el dominico Domingo Báñez (1524-1604) y el mercedario Francisco Zumel. Hasta el punto de constituir la clave del arco sobre la que se asientan las grandes polémicas acerca de la libertad humana y el concurso divino que a partir de entonces caracterizaron el pensamiento occidental, originando un debate que nunca se ha podido dar por completamente cerrado. De hecho ambas propuestas se acabarían viendo como una reedición de los anteriores planteamientos de Erasmo de Roterdam en De libero arbitrio y del propio Lutero en De servo arbitrio, habiéndose acusado respectivamente de presunción pelagiana o de determinismo teológico maniqueo, en el caso de querer retrotraer la polémica a la época de San Agustín. Además, posteriormente la polémica habría sido revisada múltiples veces, sin que tampoco se haya podido dirimir acerca de la ortodoxia o heterodoxia de las propuestas enfrentadas, por abordarse desde dos planos o punto de vista paralelos que nunca llegan a encontrarse. En cualquier caso la controversia determinó el modo como la contrarreforma católica con posterioridad al Concilio de Trento (1545-1563) afrontó una posible conciliación de este tipo de conflictos frente a la reforma protestante de Martín Lutero, habiendo sido la propia intervención papal la que terminaría optando por dejarla como una cuestión permanentemente abierta.

Pero por encima de estos planteamientos generales, João Rebalde considera que a lo largo de la polémica Luis de Molina habría recurrido a un original planteamiento condicionado a la hora de concebir los conceptos básicos puestos en cada caso en cuestión a lo largo del debate. Al menos así sucede con el uso habitual que se hace de una noción de predestinación y de reprobación igualmente condicionada, que a su vez están mediadas por distintos tipos de causas segundas, que acaban relativizando y desactivando el conflicto planteado. En efecto, si ya no es posible atribuir a la libertad de arbitrio ni a la ciencia media un posible carácter absoluto y en sí mismo incondicionado, tampoco debe ser posible confrontarlas con la correspondiente omnipotencia divina y con el consiguiente poder de juzgar. En su lugar más bien Molina habría reconocido que ambas nociones divinas y humanas se sitúan en dos ámbitos equidistantes paralelos, sin llegar a establecer un contacto entre ellos. En cambio sus opositores, Bañez y Zumel, habrían seguido proponiendo una formulación absoluta del problema planteado, abordando el conflicto desde una óptica estrictamente divina, sin acabar de apreciar la originalidad de las propuestas molinistas. Para justificar estas conclusiones la obra se divide en cinco capítulos:

1) Luis de Molina: Vida y obras. Se analizan las dificultades que en su caso hubo que salvar para la publicación de «La Concordia» en Lisboa en 1588, a la vez que se reconstruye la génesis de la controversia «de auxiliis». Se reconstruyen, además, las reiteradas acusaciones mutuas que se habría formulado ante los tribunales de la inquisición, quedando al final como una cuestión abierta a la libre discusión teológica, gracias a una laboriosa intervención de la autoridad papal;

2) El concepto molinista de libre arbitrio: su sentido y límites. Se justifica el nivel absoluto donde se sitúan la noción de libertad incondicionada divina, contraponiéndola a su vez a la noción condicionada de libertad de arbitrio en Molina, aunque distinguiéndola a su vez del simple nivel de libertad de indeterminación instintiva propia de los animales. Sus oponentes, en cambio, sitúan la libertad absoluta divina y 
la condicionada libertad de arbitrio humana a un mismo nivel, sin apreciar la originalidad de su propuesta de Molina. En este contexto se otorga a la libertad de arbitrio humana una aptitud espontánea para la realización de obras sobrenaturales, con independencia que después también requiera de una ayuda extrínseca mediante la infusión de una gracia sobrenatural, sin que en ningún caso ello suponga un pelagianismo o semipelagianismo;

3) El concurso divino. Se analizan los distintos tipos de concurso, auxilio o intervención divina, según se trate de la ayuda extraordinaria de un milagro, de una ayuda meramente sobrenatural que a su vez potencia una capacidad natural que de suyo ya tiene la criatura. Al menos así sucede con la capacidad que se otorga al hombre de evitar el mal uso de su libertad de arbitrio, como sucede en el pecado; o de potenciar en la medida de lo posible las virtudes teologales que han quedado malheridas por el pecado original; o de llevar a cabo simplemente obras virtuosas conformes a la providencia ordinaria divina;

4) La ciencia media. Se justifica el nivel absoluto donde se sitúa la ciencia divina en Boecio, en Tomás de Aquino, o en Duns Scoto, abarcando el pasado, el presente y el futuro. En estos casos la sabiduría divina se concibe fuera del tiempo, sin que se le apliquen las categorías de la temporalidad humana, salvo en las intervenciones puntuales llevada a cabo a lo largo de la historia sagrada. En cambio, la ciencia humana es una ciencia media condicionada que siempre está mediada por la situación de temporalidad en la que se pretenden materializar las ideas divinas una vez que se han encarnado en la mente humana. En cualquier caso, a la ciencia media ya no se le puede atribuir una necesidad absoluta, sino una necesidad meramente condicionada que siempre debe estar abierta a su posterior revisión crítica en razón del consiguiente ámbito empírico donde se aplican las correspondientes ideas humanas.

5) La providencia y la predestinación divinas. Se establece una separación muy estricta entre el tipo de auxilios o ayudas que conlleva el efectivo cumplimiento de la providencia y de la predestinación divina teniendo en cuenta a su vez la libertad de arbitrio condicionada que de un modo limitado se asigna al hombre. Se establecen así dos planos paralelos: por un lado, la libertad absoluta divina y, por otro, la libertad de arbitrio condicionada humana. Sólo en este segundo caso la libertad de arbitrio mantiene una dependencia respecto de determinadas causas segundas igualmente condicionadas. Hasta el punto de que la libertad de arbitrio se hace compatible con distintos tipos de auxilios o gracias sobrenaturales eficaces que a su vez también tendrán un carácter condicionado, sin que tampoco ya se pueda saber de un modo absoluto el alcance preciso que en cada caso se les debe asignar. En cualquier caso, la eficacia de la gracia sobrenatural no se contrapone a la libertad humana, sino que más bien ambas se reafirman y fortalecen, dado que la libertad de arbitrio constituye un requisito «sine que non» para que efectivamente la gracia sobrenatural pueda actuar.

Para concluir una reflexión crítica. Evidentemente el recurso a una libertad de arbitrio y a una ciencia media en sí mismas condicionadas exigió la elaboración de una lógica modal de la necesidad, la posibilidad y la contingencia, ya sea a un nivel físico, metafísico o simplemente moral. Sólo así se pudieron evitar las numerosas paradojas y contradicciones que se plantearon a lo largo de la controversia «de auxiliis», sin tener que volver a los planteamientos pelagianos, maniqueos, escotistas o simplemente luteranos habituales en estos casos. Ahí reside el acierto de la propuesta que ahora formula João Rebalde. De todos modos, convendría advertir que Luis de Molina tampoco acabó de desarrollar todas las posibles implicaciones que se derivaban de una lógica modal de este tipo. Ni tampoco de las numerosas exigencias que se derivan del carácter ilimitadamente revisable que ahora se otorga a los diversos condicionamientos a los que se pueden ver sometidos la correspondiente noción de libertad de arbitrio y de ciencia media. Probablemente acabarían siendo los también jesuitas Antonio Pérez Valiente o incluso Sebastián Izquierdo quienes terminarían desarrollando estas propuestas, que ahora simplemente se incoan. De ahí que Luis de Molina tampoco fuera capaz de cerrar las numerosas controversias que el mismo provocó.

CARLOS ORTIZ DE LANDÁZURI Universidad de Navarra 